A small circular dish is filled almost to overflowing with water the surface of which will be convex. A single floating magnet (with its axis vertical) placed on this moves at once to the centre; two or more such magnets placed on it form regular equilibrium figures, as in the usual form of the experiment. The chief interest of the modification arises, however, from the fact that the figures are not in general the same as in the ordinary arrangement. This is instructive, because it brings out clearly the necessity of knowing the exact law of force between the parts of an atom before it can be possible to predict its structure.

The experiment is so easily tried by anyone that there is no need to go into great detail here; but it may be mentioned that with the particular dish and magnets used by me it is possible to arrange ten in a single ring without any central nucleus, and that in a larger dish more can, of course, be so arranged. These ten also form stable groups as a ring of nine with one in the middle, or a ring of eight with two in the middle. But a ring of seven with three in the middle is not possible; if temporarily so placed one of the three gradually moves out and joins the seven. The first arrangement in three groups occurs for eighteen magnets in all; these are stable when placed with twelve in an outer ring, five in an intermediate ring, and a single one in the centre.

University College, London, September 17.

\section{Chemical and Electrical Changes induced by Light.}

The issue of NATURe for August 30 (p. 455) contains an abstract of a paper read before Section $A$ of the British Association by Sir Wm. Ramsay and Dr. J. F. Spencer on the chemical and electrical changes induced by ultraviolet light, in which the "fatigue" shown by certain surfaces is discussed. I have for some time been engaged in an investigation of the fatigue shown by metals for the photoelectric effect, and have made a careful examination of the rate at which the photoelectric current decays in the case of a zinc plate, polished or amalgamated. A large Nernst lamp supplied with current from storage cells was used to give a steady source of light. The decay immediately after exposure to the light was very rapid, but after about twenty minutes became much slower. For a change taking place according to the "compound interest law," as in the case of a monomolecular chemical reaction or a single purely surface effect; we know that the curve can be represented by an exponential term involving the time In the case of zinc, I find that the activity at any instant can be represented with considerable accuracy by the sum of two exponential terms. It is possible to interpret this result somewhat on the lines followed by Rutherford in explaining the decay of the excited activity of radium or thorium, by supposing that a succession of changes takes place.

Similar results have been obtained in the case of alumirtium, and also with specimens of coloured fluorspar. In the latter case the colour is attributed to the presence of particles of reduced metal.

It is interesting to note that the longer waves of light tend to produce a change in the opposite sense, so that the rapid decay at first observed on exposure to light may be followed by a small increase in activity unless the long waves are absorbed by a solution of alum.

These experiments were carried out partly in the laboratory of Lord Blythswood, to whom my thanks are due, and partly in the Wheatstone Laboratory of King's College.

King's College, London, September 21. H. S. Allen.

\section{The Rusting of Iron}

THE experiments made by $\mathrm{Mr}$. J. Newton Friend, and described by him in NATURE of September 27, confirm similar experiments previously made by me, and furnish further evidence that the rusting of iron is primarily a result of acid attack. That cast iron, a very complex No. 1927 , VOL. 747 material frequently containing a high percentage of sulphur and phosphorus, decomposes hydrogen peroxide "with astonishing rapidity," and that the metal becomes covered with rust in a few minutes, is not, however, to be referred to catalytic action, as Mr. Friend suggests, but is a consequence of the formation of acids by the oxidation of some of the impurities present in the iron, and of the subsequent electrolytic action. As Mr. Friend says, "the purer the iron the less is the action of the peroxide upon it," which is another way of stating that the intensity of action will be determined by the amount of acid formed on the surface of each particular sample of metal when in contact with the peroxide.

Cast iron is known to oxidise in air more readily than wrought iron, and this is probably due to the former containing impurities which on oxidation yield acids. The rust formed on cast iron exposed to air often contains appreciable quantities of combined sulphur.

The fact that cast iron is attacked by water in absence of air, becoming darker in colour, whilst pure iron under identical conditions remains unchanged, may also be referred to the production of a minute quantity of acid. In this case the acid is not formed by oxidation, but it is probably hydrogen sulphide resulting from the interaction of sulphides, such as silicon sulphide, contained in the crude iron, with water.

Central Technical College, October I.

\section{Remarkable Rainbow Phenomena.}

MaY I be permitted, with reference to Mr. Spence's observation of a remarkable rainbow, described in your issue of September 20, to direct attention to a number of phenomena of the same kind observed in Holland during the last ten years, and published by the Dutch Meteorological Institute in Omweders, Optische Verschijnselen enz. At Fort William, also, on August 16, 1887, a phenomenon of this sort was seen, a drawing of which is to be found in Trans. Roy. Soc. Edin. (vol. xxxiv., p. xvii, Fig. I7). Readers of NATURE will find an observation of a double rainbow, with drawing, similar to the oval described by $\cdot \mathrm{Mr}$. Spence, made by Prof. Tait on September II, I874, in the issue of October I, I874, with a comment by Maxwell upon it.

The explanation of the phenomenon is simple, and seems to have been first given by Rubenson. The upper of the two ordinary and the two secondary bows is generated by rays which enter the raindrops after reflection from a level of water situated bchind the observer. It is obvious that the altitude of the ordinary rainbow being $42^{\circ}-h$, the altitude of the one generated by reflection will be $42^{\circ}+h$, $h$ being the sun's altitude; the same holds good for the secondary rainbow. The centres of all the bows lying in the same vertical, it is clear that the two ordinary bows and the two secondaries touch each other at the horizon. For further information see my "Meteorologische Optik" (pp. $49 \mathrm{I}$ and 555).

Vienna, September 28.

\section{Fugitive Coloration of Sodalite.}

Wirf reference to the properties of Indian sodalite shown by $\mathrm{Mr}$. T. H. Holland at the York meeting of the British Association (September 27 , p. 550), will you permit me to point out that, although not generally noticed in the textbooks, the change of colour referred to is not peculiar to the Rajputana mineral. The first sodalite discovered had the same property, and Giesecké, under date August 28 , I 806 , records the occurrence of "pfirsichblüthenrothfarbene" sodalite from Kangerdluarsuk, in Greenland, "welche die hohe Farbe auf frischem Bruche sogleich beinahe ganz verliert." The same observation was made independently by Allan (Thomson's "Annals of Philosophy," I8I3, vol. i., p. 104); but I am not aware that there is any record of a recovery of the lost colour, which Mr. Holland appears to have observed.

Edinburgh, October I.
Jas. Currie. 